\title{
Conversación con Klaus Herbers entre Roma y Santiago
}

Pascual MARTÍNEZ SOPENA

Catedrático de Historia Medieval

Departamento de Historia Antigua y Medieval

Universidad de Valladolid

https://orcid.org/0000-0002-0880-7365

sopena@fyl.uva.es

De 1998 a 2019, el profesor Klaus Herbers ha ocupado la cátedra de Historia Medieval y Ciencias Auxiliares de la Universidad de Erlangen-Nuremberg. Su carrera académica había empezado en 1975 como asistente de la Universidad Técnica de Berlín. En ella se doctoró en 1980. Entre 1983 y 1998 fue investigador asociado de la Academia de Ciencias y Literatura de Maguncia, trabajando en el Proyecto Regesta Imperii en Tubinga. Precisamente obtuvo su habilitación en la Universidad de Tubinga en 1994.

Entre las líneas de investigación desarrolladas por el profesor Herbers, hay que destacar su dedicación a la historia del Papado y al culto y la peregrinación a Santiago. Su voluminosa producción registra a día de hoy unas trescientas entradas de libros, artículos y ediciones, una selección de las cuales irá compareciendo a lo largo de estas páginas.

En el pasado año 2020, el profesor Herbers fue hecho miembro correspondiente de la Real Academia de la Historia de España y recibió la Cruz Federal al Mérito, la condecoración con que el gobierno alemán premia la excelencia de los servicios civiles. No es ocioso recordar que esta condecoración tiene entre sus criterios la valoración de las realizaciones científicas extraordinarias e innovadoras, el fomento del prestigio nacional y de las relaciones de Alemania con los países europeos, y el compromiso personal por la paz y la tolerancia entre civilizaciones y creencias distintas. Tengo la impresión de que todo ello concurre en la personalidad de Klaus Herbers, junto con su ejemplar dedicación a la difusión de la cultura española.

Klaus Herbers nació en 1951 en Wuppertal, República Federal de Alemania. Wuppertal se halla en el Estado de Renania del Norte-Westfalia y es una ciudad reciente, constituida en 1929 por la unión de varias poblaciones, las más importantes de las cuales eran Barmen y Elberfeld. Como tal, es un producto de la reorganización administrativa de la República de Weimar, y su nombre -que 
significa «Valle del Wupper»-, rinde homenaje al afluente del Rhin que cruza la aglomeración. En realidad, tan breve trayectoria se superpone a la de antiguos lugares de un territorio histórico, el ducado de Berg. Durante más de ocho siglos, condes y duques de Berg gobernaron un principado cuya capital fue Düsseldorf. El penúltimo de ellos fue Joaquín Murat, que lo recibió de Napoleón por su condición de cuñado y fiel servidor del Gran Corso. Luego, el congreso de Viena de 1815 integraría el ducado en el reino de Prusia, del que fue uno de sus motores económicos: así, la empresa Bayer tuvo su origen en Barmen. Allí también había nacido Friedrich Engels, vástago de una rica familia de industriales, mientras que fue en Elberfeld donde el sacerdote Adolf Kolping inició su labor pionera de la doctrina social de la Iglesia. Símbolo de aquella época es el Schwebebabn o «tren colgante», un transporte público que circula suspendido sobre el río y las calles de la ciudad a lo largo de trece kilómetros.

La cara adversa de su pujanza fueron los masivos bombardeos que sufrió la zona durante la II Guerra Mundial; por ejemplo, más del 40\% de los edificios de Wuppertal quedaron destruidos. No hay que olvidar que en la ciudad se reflejan otros aspectos de la historia alemana del XX, compleja y trágica. A modo de metáfora, cabe recordar que entre sus hijos figuran Grete Stern -la gran fotógrafa cuya condición de judía la obligó a exiliarse en Argentina-, Arno Breker -uno de los escultores preferidos del nazismo-, y Johannes Rau, el político de profunda espiritualidad que ocupó la presidencia de la república en el tránsito a nuestro siglo.

\section{UN BREVE EJERCICIO DE EGOHISTORIA}

Pregunta. Rainer Maria Rilke escribió que la verdadera patria del hombre es la infancia. ¿Lo piensa asi Klaus Herbers, viajero impenitente y estudioso del viajar? En todo caso, ¿qué recuerdos siente más intensamente cuando evoca su niñez en Elberfeld y sus estudios en Solingen?

Respuesta. Yo vivía al oeste de Wuppertal, en el ámbito de la parroquia de Vohwinkel. Esta era un centro con cierto éxito, muy activo, la parroquia originaria de varios obispos auxiliares de Colonia dinámicos y estrictos. Hay que entender que en Wuppertal viven pocos católicos, lo que estimulaba cierta solidaridad religiosa. Los chicos estábamos juntos en clase pero, en el tiempo libre, los de cada confesión iban con los suyos...

P. Klaus Herbers rememora. Eran los tiempos de Monseñor Frings, el cardenalarzobispo de Colonia que en la postguerra había comprendido desde el púlpito que la población robase briquetas de carbón ferroviario para calentarse. Desde entonces, al robo 
por necesidad se le llamaba en alemán fringsen. La larga vida del arzobispo alcanzó a darle protagonismo en el Concilio Vaticano II, donde tuvo como consultor teológico a un joven foseph Ratzinger.

R. Mis estudios en Solingen -prosigue-, fueron muy felices, junto a mi hermano mayor. Tuvimos una buena formación en el colegio, en un periodo de cambio de los planes de enseñanza. Mi familia provenía de la Baja Renania, cerca de la frontera holandesa, una región donde católicos y protestantes se hallan muy mezclados. Mi abuelo materno fue maestro en Wuppertal. Mi padre se estableció aquí después de la segunda guerra mundial, y aquí conoció a mi madre.

P. La formación universitaria de Herbers abarcó la historia, la filología románica y la filosofía. Desarrolló sus estudios en tres universidades -la cercana Colonia, luego Poitiers y Saarbrücken. Esto es algo que para el universitario medio español de los años 1970 puede resultar más singular. Aunque, hacer una especie de recorrido universitario como éste ¿era frecuente en Alemania? En su caso, ¿Qué le impulsó a hacerlo?

R. Esta trayectoria no era lo que hacía todo el mundo, pero sí era frecuente. Es algo así como cambiar de sitio para conocer más profundamente lo que te va interesando. En definitiva, vas definiendo lo que te atrae y buscas donde puedes aprenderlo mejor. Yo pasé en Colonia los dos primeros años, pues esta era la universidad más cercana. Pero para estudiar filología románica, estuve un semestre en Poitiers. Por cierto, también hice un curso de verano de seis semanas en $\mathrm{Pa}$ lencia para aprender español. En la misma línea, la continuación de mis estudios en Saarbrücken se asocia a que elegí un ambiente cercano al mundo francófono.

P. En cuanto a las grandes lineas de su formación y sus profesores, ¿Desea seleccionar nombres, materias y orientaciones relevantes? Me refiero a lo que ha marcado su investigación posterior.

R. Me interesaron mucho las clases de Theodor Schieder y Theodor Schieffer en Colonia, especialistas en historia moderna y en la edición de cartas del mundo carolingio, así como las de Egon Boshof. Luego, en Saarbrücken fui alumno de Harald Zimmermann. Pero algo que definió mi interés por la peregrinación y su historia, fue mi estancia en Poitiers. Allí, Edmond-René Labande dirigía el Centre d'Études Supérieures de la Civilisation Médiévale. En sus seminarios se trataba de la literatura medieval -de los cantares de gesta al Roman de Renart-, y había en ellos cierta iniciación al mundo jacobeo. Estando en Colonia, ya había tenido ocasión de peregrinar a Nôtre Dame de Chartres. Volví a hacerlo y entonces conocí a gente de París que me hablaron del Camino de Santiago. Con algunos de ellos tuve ocasión de recorrerlo.

De todas formas, el Camino era muy poco conocido en esos años, y los peregrinos, muy escasos. No había indicaciones seguras en Francia ni en España que 
permitieran seguirlo con precisión. La gente era muy simpática a la hora de recibir a los peregrinos, pero casi nunca había nada más, ni información, ni memoria viva. Recuerdo que, a nuestra llegada a Santiago, las chicas fueron alojadas en las benedictinas de San Payo de Antealtares, mientras yo fui acogido en el convento de San Francisco. Eso sí, se mantenía la tradición de dar de comer a los peregrinos en el hospital-parador de los Reyes Católicos, en la plaza del Obradoiro.

P. Como se ha adelantado, su tesis doctoral sobre el Liber Sancti Iacobi fue presentada en la Technische Universität de Berlín en 1980. Estuvo supervisada por los profesores Harald Zimmermann y Ernst Pitz. Sobre todo, el primero era un gran estudioso de la historia de los papas y de sus documentos. Fue profesor de Saarbrücken en los tiempos en que Vd. era estudiante, y después pasó a Tubinga. También estuvo vinculado a los proyectos Regesta Imperii, y participó activamente en el ambiente de las Academias, como usted mismo en Maguncia y Gottinga. Por otra parte, él procedía de esa peculiar sociedad que fueron por siglos los «sajones de Transilvania», gentes germánicas entre magiares, rumanos y otros, a los que también dedicó una parte de sus estudios... Uno tiene la impresión de que el interés por la interculturalidad, por la historia de los papas y por la diplomática, con su largo vínculo y su responsabilidad en Regesta Imperii, muestra ciertos paralelos entre ustedes dos: ¿es apropiado considerar que H. Zimmermann fue para usted un maestro en el pleno sentido de la palabra? Me refiero a esa irradiación que se produce después de licenciarse ¿Puede evocar la influencia que tuvo en Vd.?

R. En efecto, las raíces de Harald Zimmermann estaban en el Este y él tenía nacionalidad austríaca. Fue un estudioso de la historia del papado, a la que le introdujo su maestro Leo Santifaller, tirolés del sur que se había movido entre el mundo germánico y el italiano. Y en efecto, se interesó por su país de origen y algo menos por Italia. En cambio, no se ocupó de España ni del culto de Santiago. Era casi una terra incognita para él.

P. ¿Y sobre su experiencia en Regesta Imperii?

R. El sistema de Regesta Imperii es una invención de Johann Friedrich Böhmer en el siglo XIX. Resume la preocupación por las fuentes escritas. Pero editar todos los documentos es costoso. En vez de editar pieza a pieza, concibe regestos. Establece un sistema cronológico a base de reyes y reinados... En estos momentos, coordino el trabajo. Además, tengo en él una labor bien definida: el estudio de los papas del siglo IX. En breve va a ser publicado el registro del pontificado de Adriano II (867-872), un papa importante del que existe una densa documentación.

La parte más utilizada de Regesta Imperii es hoy en día su compendio de bibliografía, nada menos que dos millones y medio de referencias. Pero desde el punto de vista interno, esta labor ocupa a una sola persona. En cambio, el estudio 
de las fuentes y los acontecimientos -hoy, la gran empresa es la digitalización de las fuentes-, cuenta con diez colaboradores en Alemania, más los de Austria... Bastan los números para dar idea del peso relativo de las directrices que estamos desarrollando.

\section{MARCOS Y ESTRUCTURAS DE LA INVESTIGACIÓN Y LA SÍNTESIS}

P. Cuando el profesor Herbers cumplió 65 años (2016), sus colegas y amigos junto con sus discípulos recientes contribuyeron a un libro-bomenaje que tiene un título breve

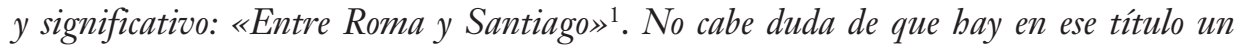
esfuerzo por sintetizar las líneas primordiales que él ha cultivado dentro del vasto campo de la historia eclesiástica y religiosa de la Europa medieval: la historia del pontificado, con una clara orientación hacia la ciencia diplomática, y la peregrinación a Compostela, como fenómeno de masas y, al mismo tiempo, como vivencia individual. Las mismas ideas presiden el volumen que reúne su selección personal de 17 estudios editada en 2017, aunque con una clara dimensión bispánica².

Roma y Santiago: en estas dos obras misceláneas se resumen decenios de labor y de reconocimiento creciente, recorridos por una voluntad de reunir y depurar la información, de reinterpretar las fuentes escritas a la luz de las ciencias sociales. ¿Tal vez ambos motivos y sus ramificaciones (la experiencia de los viajeros, la irradiación de Roma), están

1 Claudia Alraum, Andreas Holndonner, Hans-Christian LeHner, Cornelia Scherer, Thorsten SCHLAUWITZ, Veronika UNGER (Hrsg.), Zwischen Rom und Santiago. Festschrift für Klaus Herbers zum 65. Geburtstag. Beiträge seiner Freunde und Weggefährten, dargereicht von seinen Schülerinnen und Schülern, Winkler, Bochum, 2016. La cubierta está decorada con el sector del mapamundi del «Beato de El Burgo de Osma» (1086), donde se representan España e Italia. Es un homenaje muy plástico a Santiago, Compostela y Galicia, así como a Roma y los santos Pedro y Pablo. Su contenido se distribuye en seis secciones tituladas «la Península Ibérica en la Edad Media», «peregrinos y profecía», «santo y santos», «Papado, Roma y Curia» y «biografía y ciencia histórica». Las 28 contribuciones están firmadas por un elenco de historiadores germánicos, a los que se suman algunos italianos y franceses. La especialidad de los autores conduce a escenarios tan lejanos como China o tan cercanos como el suroeste alemán.

2 Klaus Hebers, Papado, peregrinos y culto jacobeo en España y Europa durante la Edad Media, Editorial Universidad de Granada [Col. Historia], Granada, 2017, 380 pp. Esta colección se ha venido caracterizando por publicar obra selecta de autores consagrados por sus líneas de investigación, cada uno de los cuales hace su propia selección de artículos. Los 17 estudios de Klaus Herbers pautan 25 años de publicaciones dedicadas al fenómeno jacobeo desde el siglo X: el culto al apóstol, sus perspectivas y su eco en Alemania, la sede apostólica de Compostela y sus relaciones con la monarquía y el papado, el carácter sacro del Camino, el Códice Calixtino y las diversas vertientes de la literatura de viajes, la que su colega Paolo Caucci von Saucken denomina «literatura odepórica». 
en la base de una tercera línea de investigación? Me refiero a la bistoria transcultural, el contraste y la articulación entre civilizaciones. Gran parte de lo cual tiene su banco de pruebas, su escenario privilegiado, en la España medieval, sin menoscabo de una mirada intensamente germánica.

R. Hay una gran relación entre Roma y Santiago. El éxito de Santiago en gran parte dependió de aceptar la autoridad romana. Diego Gelmírez aprovechó mucho la autoridad romana para conseguir el reconocimiento universal de la tumba, la dignidad arzobispal, etc., etc.

Y en este contexto se plantean perspectivas de las ciencias sociales. ¿Qué relaciones tiene la historia de la Iglesia y la economía en todo esto? Los peregrinos, la circulación monetaria y la concentración de riqueza en Compostela constituyen una ilustración relevante. ¿Europeización de la Península? La historia trata de personas, y la circulación de gentes ha asegurado los intercambios entre Roma y Santiago. Conocer las personas y sus acciones nos da una visión más profunda de la evolución de los contactos entre Roma y Santiago. En fin, los jubileos de Roma, el año santo compostelano y Aquisgrán son grandes acontecimientos culturales y grandes fenómenos en lo religioso, grandes momentos para el perdón. En este sentido hay que recordar la importancia primordial de las indulgencias para la gente de la Edad Media, tan preocupada por la vida en el más allá.

P. Una segunda impresión es que todo ello da cuenta de cómo $V d$. ha cumplido con el objeto de la cátedra que ba ocupado en Erlangen-Nuremberg, «Historia Medieval y Ciencias Auxiliares». Su investigación refleja una gran conexión entre el bistoriador y el paleógrafo-diplomatista...

R. Esta combinación es habitual en Alemania. Conozco pocos casos de cátedras exclusivas de Ciencias Auxiliares, esto es, Paleografía y Diplomática. Solo las de Munich y Bonn, y están en trance de extinguirse. Pero no hay una distribución de tiempo equilibrada: se puede decir que dedicamos el $80 \%$ a la historia y el $20 \%$ a paleografía y diplomática. Esto significa que en la universidad aprendes a leer las fuentes que te servirán para interpretar la historia, pero no profundizas en las propias ciencias auxiliares. Lo cual es sobre todo labor de la investigación especializada posterior.

P. Klaus Herbers ha trabajado asiduamente desde la perspectiva de las instituciones (y entre ellas, destaca el papado, pero también el prisma diocesano). En principio, se podría pensar que basta la consistencia de las fuentes escritas asociadas con ellas: esto es, un relato al bilo de los numerosos diplomas y demás elementos legados por un pasado sobresaliente... Por eso es muy importante captar otras reflexiones que eventualmente se deslizan en su obra. Para el caso, cómo reflexiona sobre la importancia de las ciencias 
sociales, una llave para acercarse a este «mundo extraño» que es el mundo medieval ${ }^{3}$. Me gustaría escucharle reflexionar sobre el interés de las ciencias sociales para la formación del medievalista. Pero no solo sobre ello. Vivimos un tiempo en que el conocimiento de la lengua latina, que para su trabajo ha sido una herramienta clave, ve reducido el número de sus cultivadores: ¿Han ensayado fórmulas eficaces para incorporarlas a la formación de los historiadores medievalistas?

R. El conocimiento de la lengua latina es la herramienta básica para investigar en historia medieval. En la mayoría de las universidades alemanas se exigen conocimientos de latín. Muchos de los universitarios alemanes han podido cursar hasta 5 años de latín en el Gymnasium, la enseñanza preuniversitaria: incluso 7 o 9 años para los estudiantes con Mención de Lenguas Clásicas y Humanidades. Si faltan conocimientos, hay que hacer un curso de dos años en la universidad, que proporciona un nivel mínimo. Aunque debo precisar: se trata con frecuencia de cursos de verano rápidos.

Conociendo esta lengua y otras, los alumnos pueden acceder a los saberes de las ciencias sociales con poca dificultad. Mientras una sólida base lingüística es un instrumento perdurable, las ciencias sociales dependen de escuelas y cambios de perspectivas. Desde luego -añade con cierta socarronería-, para acceder a las nuevas miradas de las ciencias sociales, hay que entender lo que está escrito en las fuentes.

P. Vivimos una época en que la informática se percibe como una berramienta de futuro. Vds., también la han incorporado a su labor habitual. ¿Consideran que está mejorando la calidad de las ediciones de textos, la articulación de las informaciones, la agudeza de las interpretaciones?

3 He introducido un largo párrafo suyo donde expresa su punto de vista, que él reconoce como matizado, incluso ambivalente. «Si el tiempo de la oralidad, de lo arcaico, tenía una lógica muy distinta a la de los tiempos modernos, parece evidente que bajo la influencia del linguistic turn, del culturalismo, de la sociología y de la etnología, la interpretación de la documentación obtenga resultados distintos. La perspectiva de las fuentes, la regularidad de los rituales según reglas no escritas, son consecuencias directas de estos supuestos. La suposición subyacente en la mayoría de los nuevos estudios era una nueva evaluación del «rendimiento» de las fuentes conservadas hasta el día de hoy... Quizá hayamos pedido demasiado a estas fuentes... la intencionalidad de las fuentes era sobre todo la memoria y la liturgia y no la legitimidad de los reyes... Pero también con esta posición... nos cerramos a la posibilidad de que los autores de las fuentes tuvieran intenciones diversas y a la posibilidad de que los textos se pueden leer a varios niveles». Klaus HERBERS, El Imperio entre Otón I y Conrado II. Interpretaciones y tendencias de la historiografía actual, en Ante el Milenario del reinado de Sancho el Mayor. Un rey navarro para España y Europa (Actas de la XXX Semana de Estudios Medievales. Estella, 14-18 julio 2003), Gobierno de Navarra, Pamplona, 2004, pp. 375-376. 
R. Algunas cosas son útiles, aunque conviene ponderar. Me parece extraordinariamente útil el método informático «Pattern recognition», que está permitiendo sistematizar el análisis paleográfico, y hay otras varias perspectivas de utilidad. La identificación de escribanos se hace más precisa. Las bases de datos que permiten tratar estadísticamente los documentos, aunque los textos deben ser cuidadosamente leídos... Por otra parte, las ediciones electrónicas permiten comparar tradiciones textuales de determinadas fuentes, y esto facilita el trabajo y economiza esfuerzos.

P. La ambición de los proyectos revela una gran capacidad no solo para enunciar grandes cuestiones, sino también para trabajar en equipo, y para formar un grupo de investigadores avanzados. Esta es una de las bases del desarrollo de la investigación. A lo largo de un cuarto de siglo, sus sucesivos proyectos dan cuenta de un buen número de colaboradores que ban participado en su elaboración cumpliendo papeles concretos.

No tengo duda de que enseñanza e investigación se retroalimentan. Que los profesores universitarios tienen la gran fortuna de mejorar su investigación (y la forma en que trasmiten su investigación) gracias a la práctica docente. Tampoco dudo de que la investigación en ciernes se pule reflexionando en voz alta y escuchando las observaciones que suscita en las horas de clase, en los seminarios, en los trabajos de campo... Es verdad que hay excelentes divulgadores que no han desarrollado una tarea de investigación propiamente dicha, y que grandes investigadores tienen dificultades para mantener el interés del público estudiante. Pero en conjunto, la asociación de los dos componentes funciona y fructifica. Ahora bien, ¿cómo se articulan ambas vertientes en su trabajo de universitario alemán?4.

R. Conviene tener en cuenta que, en Alemania, los proyectos de investigación son valorados especialmente si incluyen jóvenes investigadores. Por lo tanto, mi capacidad de organización se ha asociado siempre con las posibilidades.

Pero además, hay que ligar investigación y enseñanza. Mi labor docente se sitúa dentro de cierta tradición que se remonta a los seminarios de la universidad de Humboldt: enlazar investigación y enseñanza, algo así como una «enseñanza

4 Recojo un testimonio muy interesante de nuestro autor, cuyo motivo son la hagiografía y los milagros: Klaus Herbers, Lenka JirousKovÁ, Bernhard VOGEL (eds.), Mirakelberichte des früben und bohen Mittelalters, Wissenschaftliche Buchgesellschaft, Darmstadt, 2005. El libro contiene una antología de textos formado por 12 dossieres que recogen la variedad interna de la hagiografía. Se presenta como resultado de un seminario de enseñanza desarrollado en la Universidad de Erlangen. La obra traduce una profunda preocupación didáctica, centrada en la metodología del análisis de los textos y en reflexionar sobre su aportación para la investigación histórica. 
investigativa». De forma que mis alumnos han conocido y han participado de mi investigación como un método pedagógico.

P. $V d$. ha hecho una importante labor de alta divulgación. Es decir, de obras de sintesis. Esta no es una cuestión menor, tanto si se valora desde la labor pedagógica del profesor universitario (a lo que ya se ha aludido), como del especialista que pone a disposición del público interesado visiones sintéticas de grandes problemas. Tengo la impresión de que algunos de sus estudios sobre el papado medieval pueden entrar en esta consideración, así como otros relativos al Camino de Santiago, o su libro sobre la historia milenaria del Sacro Imperio Romano Germánico ${ }^{5}$. Pero aquí deseo subrayar su bistoria de la España medieval y a su colaboración en la bistoria de Portugal, una obra realizada junto con Walther L. Bernecker ${ }^{6}$. Ambos trabajos destacan el papel primordial de la Iglesia en la bistoria medieval europea a través de un gran escenario regional, una cuestión sobre la que volveremos después.

R. Considero esta tarea sumamente importante. En general, el objetivo es generar interés por la historia y los problemas que plantea la historia a un público muy vasto. En concreto, nuestro trabajo sobre el Sacro Imperio tenía como objeto explicar el milenio de historia del Sacro Imperio Romano-Germánico a través de sitios que habían servido como escenario de su trayectoria. Pero en términos más específicos, los libros sobre España y Portugal pueden considerarse también manuales que sirven para la preparación de los exámenes de los estudiantes universitarios. Hay que tener en cuenta que no había una historia actualizada de la Península Ibérica (la que escribió Ludwig Vones, tiene más de treinta años).

P. También ha conducido grandes proyectos a lo largo del tiempo. Su mejor ilustración son los libros que ba escrito y coordinado. A su alrededor se ba movido un amplio grupo de investigadores. Sus nombres firman artículos en muchos de esos libros o figuran como colaboradores. ¿Tal vez sea inoportuno preguntar si existe una «escuela Herbers», vinculada por preocupaciones científicas comunes, por lazos personales, e incluso por el aire de Erlangen, de Roma o de Compostela...?

R. Hay vínculos personales. Pero no puedo juzgar que haya una «escuela». Pienso que mis alumnos son muy variados. No considero que exista una «escuela» en el sentido que suele darse a este término. En cambio, sí que estimo que he-

5 Das Heilige Römische Reich. Schauplätze einer tausendjährigen Geschicbte (843-1806) (en colaboración con Helmut Neuhaus), Böhlau, Colonia, 2005.

6 Klaus Herbers, Geschichte Spaniens im Mittelalter. Vom Westgotenreich bis zum Ende des 15. Fabrbunderts, Kohlhammer, Stuttgart, 2006. Walther L. BERNECKER - Klaus HERBERS, Geschichte Portugals, Kohlhammer, Stuttgart, 2013. 
mos hecho mucha labor en los diferentes campos que me han ocupado, siguiendo metodológicamente la misma línea de trabajo.

P. En todo caso, Vd. y los suyos han desarrollado su tarea en un marco institucional que, como todos los marcos, tiene sus reglas y sus exigencias. ¿ Hay un «modelo alemán» para la investigación en humanidades, desde los planes científicos a los contratos de trabajo, pasando por las instalaciones mínimas requeridas o los controles de calidad? La cuestión tiene seguramente muchos matices. En todo caso, ¿qué rasgos caracterizarían al supuesto «modelo»? ¿Cuáles son sus fortalezas, y qué debilidades percibe Vd.?

R. Tampoco se puede decir que exista un modelo alemán (y mucho menos inmutable). Un ejemplo: hace 30 o 40 años, en la universidad había una perspectiva clara, una carrera que conducía de la tesis y la habilitación a la cátedra. Rutas secundarias a lo largo del tiempo conducían al trabajo en el archivo, la biblioteca o el Gymnasium. En nuestro terreno, aparte del sistema clásico y de la fórmula reciente junior professor, hay posibilidades para los jóvenes investigadores a través de proyectos que se encauzan a través de academias como la de Maguncia y Gottinga y de la Deutsche Forschungsgemeinschaft... Pueden llegar a durar hasta 15 y 20, incluso 25 años. Pero es difícil pasar de ellos a una carrera académica clásica.

Por otra parte, me parece muy interesante la fórmula que se puede traducir como «colegio internacional para la investigación en humanidades». Con $\mathrm{Mi}$ chael Lackner, mi colega sinólogo de Erlangen, dirigimos el proyecto «Destino, Libertad y Predicción», pensado para analizar los pronósticos en la Edad Media, desde el extremo Oriente a la Europa occidental, lo que nos ha permitido contratar por semestres a fellows que no pertenecen a nuestra propia universidad.

Pero un problema suplementario nubla las perspectivas posteriores para mantenerse en la universidad: la dificultad de conseguir dotaciones de cátedras y profesorado de Historia Medieval. En estos momentos, están en expansión la historia moderna y contemporánea, y las ciencias sociales. Materias como la historia medieval tienen dificultades para crear puestos de trabajo.

\section{ROMA Y EL PAPADO}

P. Klaus Herbers es valorado como uno de los grandes especialistas del papado medieval. Su tesis de habilitación en Tubinga versó sobre el Papa León IV (847-855), el pontífice que, tras la devastadora incursión sarracena de 846, bizo amurallar la colina del Vaticano (por lo que desde entonces se la conoce como la «Ciudad Leonina»). Desde 2006, ostenta el cargo de Secretario General de la Fundación Pius, que nació del vínculo 
entre Pio XI y Paul Fridolin Kebr, cuya tarea es la investigación de documentos pontificios. Más allá de lo cual, publicó bace unos años una historia del papado en la Edad Media, prolongada con una bistoria de los papas medievales y renacentistas ${ }^{7}$.

El papado es una institución con veinte siglos de historia, e historia significa tradición y evolución. ¿Qué características le parecen más relevantes para definir al Papado medieval?

R. Me parece que el Papado ha tenido sucesivas etapas en la Edad Media, y en ellas destaco la personalidad de grandes pontífices romanos. En el siglo V, León I. En el VI-VII, Gregorio el Grande. En el IX, bajo los gobiernos de León IV y Nicolás I se define la noción concepcional de «primado de la sede apostólica». Luego en el siglo XI cristaliza la Reforma gregoriana, que hace del papado una institución paneuropea. El XII es el siglo del derecho canónico y de la integración religiosa, desde Portugal a Polonia, de Italia a Suecia...

¿Cómo se podría definir al Papado? Es una institución muy «global» sobre todo desde la época de las Cruzadas, que integra varias influencias y al mismo tiempo trasfiere a otras instituciones su forma de funcionar. Un ejemplo de esto es cómo el sistema de elección del pontífice por los cardenales, que se consolida en el siglo XII, será copiado más tarde en el sistema electivo del Sacro Imperio Romano-Germánico, a través de los 7 electores que eligen al Emperador.

Pero abandonemos el periodo medieval. Mucho más decisivo es considerar que a base de sus raíces medievales, el papado impulsará desde el siglo XVI la acción misionera, uno de los grandes instrumentos de la globalización. Podemos decir que lo que llamamos hoy la «historia global», esta nueva forma de mirar la evolución del mundo, tiene en el Papado uno de sus capítulos más importantes y expresivos.

Por otra parte, la pregunta se dirige a la capacidad de adaptación del papado a lo largo de veinte siglos. Yo subrayaría que la institución papal se ha caracterizado por las posibilidades de integrar tendencias dentro de la Iglesia. Pensemos en dos casos muy distintos. Uno, la integración de los franciscanos medievales, que se produjo en un tiempo en que existía mucha tendencia a las herejías. El papado hizo un gran esfuerzo por integrarlos, dado que se movían en los márgenes de la fe oficial. Otra vertiente es la experiencia de inculturación de la Iglesia de América del Sur, desde el siglo XVI hasta los tiempos actuales.

P. Como decimos vulgarmente en España, voy a llevar el agua a mi molino. El comité organizador de las Semanas de Estudios Medievales de Estella ha tenido ocasión

7 Klaus Herbers, Geschichte des Papsttums im Mittelalter,, Wissenschaftliche Buchgesellschaft Darmstadt, 2012; posteriormente, ID., Geschichte der Päpste im Mittelalter und Renaissance, Reclam, Stuttgart, 2014. 
de invitarle dos veces en estos últimos veinte años. Se acaba de aludir a la primera, en 2003. Nuestra reunión estaba dedicada al milenario del rey Sancho III el Mayor de Pamplona: «un rey navarro para España y para Europa», propuso como subtítulo el recordado presidente del comité, don Angel Martín Duque. Y en efecto, el coloquio procuró trazar un perfil complejo y amplio de los diversos escenarios del mundo cristiano de su tiempo, desde los rasgos de la coyuntura a los personajes singulares. Como se ha visto, Vd. tuvo a su cargo la ponencia dedicada al Sacro Imperio. Resalto abora otra de sus apreciaciones: $V d$. criticaba que tradicionalmente no se ha valorado bien el papel del papado en tiempos de los emperadores sajones y salios (es decir, de comienzos del siglo X al siglo XII). No obstante, apreciaba una revaloración reciente (de la que se sentía parte). No dudó en señalar que «la Europa cristiana se formó sobre todo a partir de Roma», y a través de la religiosidad...

R. En la línea de la pregunta anterior, partamos de un ejemplo de fines del siglo IX, el proceso del Papa Formoso y la discusión posterior, que cristalizó en un paradigma: el pontífice romano no es un obispo como los otros, pues Roma es una sede especial, y su cátedra posee un estatus excepcional. De suerte que la prohibición de traslado no se practicó en adelante con la sede romana ${ }^{8}$... Pero antes de este episodio, el planteamiento sobre la singularidad del Papa de Roma se percibe en el siglo IX a través de las cartas de Nicolás I, Adriano II o Juan VIII, donde se aprecia cierto impulso: que Roma decide por el Occidente cristiano. Es el mismo que enlaza con las perspectivas de Silvestre II, el pontífice del año 1000. En definitiva, todo ello forma parte de una larga preparación para la europeización y la globalización a que acabamos de aludir con la reforma gregoriana del siglo XI, y para la consolidación del Papa de Roma en el siglo XII.

P. Comentamos que hace cinco años de la segunda vez que vino a Estella, en 2016. Su ponencia se tituló «La fuerza innovadora del papado en los siglos XI y XII. El acceso al trono papal»: el acceso al trono en la Europa medieval era el eje de nuestra reunión. Aquí subrayó cómo el papel de los cardenales en las elecciones papales del siglo XII es un signo de la importancia del orbe cristiano frente a una larga tradición de imposiciones a cargo de las fuerzas vivas de la ciudad de Roma (o del monarca del Sacro Imperio). Pero en

8 El papa Formoso (891-896), fue sometido a un proceso póstumo que culminó con su deposición simbólica, la invalidación de sus actos y el ultraje de su cadáver (en el «Sínodo cadavérico» de 897). El argumento principal contra el difunto pontífice fue que, siendo obispo de Portus (la ciudad portuaria de Roma), había obrado para convertirse en obispo de Roma. El derecho canónico impedía que los obispos se trasladaran de una diócesis a otra, entendiendo que cada prelado había establecido un vínculo perpetuo con su sede. Como se puede apreciar, la memoria de Formoso quedó absuelta al cabo de pocas décadas. 
realidad, destacó un proceso de reciprocidad entre Roma y el mundo católico. Pues, si bien los principes de la Iglesia determinan la elección del pontífice romano, Roma se lanza a la conquista del orbe cristiano sirviéndose de cartas papales, legaciones y jueces delegados, así como del derecho romano redescubierto y del derecho canónico. Uno de los efectos que destacó fue que, desde 1179, se acabaron los antipapas hasta el gran Cisma, dos siglos después. No obstante, coincidimos en que esto se produjo en unas condiciones completamente diferentes.

Como se ha indicado antes, Klaus Herbers es el Secretario de la Fundación Pius desde hace más de 15 años. Está editando de nuevo la obra de Philipp Faffé, esto es, la Regesta Pontificum Romanorum que el gran erudito alemán publicó en Berlín (1851), incluyendo 11.000 documentos. La $2^{a}$ edición, póstuma y ampliada, se bizo en Leipzig entre 1885-1887, y sirve como base de la actual.

Estamos hablando de hace mucho más de un siglo. En este periodo, la publicación de fuentes ha progresado mucho... ¿Puede resumir las novedades que la nueva edición de las cartas papales ha representado, que ya ha publicado 4 tomos?? ¿Cabe hacer previsiones sobre la edición de los tomos siguientes? Tengo la impresión de que ban ampliado lo que pudo ser un estudio de cartas papales a toda la información sobre los sucesivos papas.

R. En realidad, el trabajo sobre la obra de Jaffé es casi una iniciativa colateral dentro de los esfuerzos para re-evaluar la visión general del Papado a través de los otros grandes proyectos, Regesta Imperii, Germania Pontificia, Italia Pontificia, Gallia Pontificia, etcétera. El principal interés es dar una visión general cronológica de todo lo adquirido durante más de cien años. Nuevos textos, nuevas indicaciones de contactos papales en la historiografía... Y así incrementamos el número y la variedad de referencias.

En estos momentos se está preparando el volumen V. Ya se ha acabado el papado de Gregorio VII y Víctor III, y se está trabajando con Urbano II, el gran papa de la Primera Cruzada, con lo que llegaremos al año 1099. Pero éste va a ser el último que se imprimirá de forma tradicional.

9 Vaya como ilustración uno de los tomos editados recientemente: Philip JAFFÉ, Klaus HERBERS (ed.) Judith WERNER (adapt.), Regesta Pontificum Romanorum. Tomus Quartus (ab a. MXXIV usque ad a. LLXXIII), Vandenhoeck \& Ruprecht, Gottinga, 2019. Reúne la documentación pontificia desde Juan XIX a Alejandro II (esto es, entre 1024 y 1073). De acuerdo con la tradición, los regestos en latín siguen un riguroso orden cronológico. El número de entradas supera las 2.500; su incremento respecto a la edición de Jaffé se debe al hallazgo de nuevas bulas, la inclusión de cartas dirigidas a los papas, y la suma de noticias procedentes de fuentes narrativas. Por otra parte, éste es un periodo capital en el proceso de Reforma de la Iglesia, con su cortejo de actas conciliares y documentos legales. Por otra parte, hay que destacar que un siglo de bibliografía y crítica diplomática enriquecen sustancialmente a la nueva edición. 
Siento un tanto que cuando termine el proyecto financiado por las academias alemanas a fines de este año, no haya culminado la tarea de alcanzar la fecha de 1198, la que corresponde a la Regesta Pontificum Romanorum. Pero ya se trabaja con distintas soluciones. En primer lugar, se va a publicar en la red toda la información suplementaria a la segunda edición de Jaffé y la referente al papado hasta 1159 , tanto la de las cartas como la de cualquier otro tipo de fuente escrita. En segundo lugar, varias colegas han pedido un proyecto para trabajar en la gran masa de documentos del gobierno del papa Alejandro III (1159-1181). En fin, para el periodo 1181-1198, se cuenta con los volúmenes de Regesta Imperii hasta Celestino III (1191-1198), también accesible a través de las páginas web papsturkunden. de y Regesta Imperii.

Todo ello subraya la importancia de la Red para el futuro. En la Red también ya se hallan muchas publicaciones anteriores digitalizadas, y sobre todo, un banco de datos actualmente de los tomos I y II de la Regesta Pontificum Romanorum. Esto será interesante a escala mundial para quienes no disponen de los volúmenes impresos.

P. Le he pedido reflexionar en dos direcciones a partir de estas propuestas: una es fundamentalmente bistórica, y la otra, diplomática. En conjunto, la primera se detiene especialmente en la Península Ibérica a través de tres obras, dirigidas por él, sobre la relación de Roma con los reinos hispánicos en la Plena Edad Media. Las tres son resultado de sendas reuniones científicas, cuya coordinación aseguró junto con otros estudiosos ${ }^{10}$.

Tomemos la última como ejemplo. Su título, «El papado limitado», estudia el «alcance de la acción papal», deteniéndose en el papel de los Legados y de los jueces delegados, así como en los problemas de límites territoriales, que son a la vez eclesiásticos y políticos. Estos temas habian sido objeto de una reunión celebrada en la Universidad Católica Portuguesa de Lisboa (2010), a la que concurrieron un buen número de expertos (sobre todo alemanes) en la historia del Papado y de la península ibérica (eje geográfico del encuentro). Es oportuno señalar que la obra se diseñó con categorías propias de la bistoria cultural (me refiero a los conceptos-marco como «centro», «centralismo», «trasferencia», «comunicación»), en coherencia con preocupaciones de su editor.

10 Klaus Herbers y Santiago Domínguez SÁNCHEZ (eds.), Roma y la Península Ibérica en la Alta Edad Media. La construcción de espacios, normas y redes de relación, León, Universidad de León, 2009. Klaus HERBERS y Ingo FlEISCH (eds.), Erinnerung - Niederschrift - Nutzung. Das Papsttum und die Schriftlichkeit im mittelalterlischen Westeuropa, De Gruyter, Berlin, 2011. Sobre el papado y la alfabetización de la Europa medieval. Klaus HERBERS, Fernando LóPEZ ALSINA y Frank ENGEL (eds.), Das begrenzte Papsttum. Spielräume päpstlichen Handelns. Legaten - delegierte Richter - Grenzen, Berlin, De Gruyter, 2013. Sobre el alcance la acción papal, sus legados, los jueces delegados y los problemas de límites y demarcaciones. 
Tras estas obras se hace visible un programa sistemático de investigación, desarrollado a través de varios proyectos y en función de colaboraciones solicitadas y precisas. Ahora, al cabo del tiempo, ¿puede hacer balance de los resultados?

R. En efecto, el gran objetivo de estos encuentros fue ordenar y clasificar lo que se estaba y aún se está trabajando en el proyecto Iberia Pontificia. Dicho de otra manera, estos volúmenes acompañan a esta tarea en pro de sistematizar las líneas de evolución que se produjeron en la Península Ibérica en el siglo XII. Conceptos como los citados -centro y periferia, trasferencias-, o el proceso de introducción del derecho canónico en las iglesias hispánicas, funcionan bien, pero necesitaban ser contrastados. Había que precisar. En 2010, cuando celebramos la reunión de Lisboa, teníamos claros los conceptos, aunque si examinamos las situaciones concretas, todo resulta más complicado. Pero así es el proceso de la investigación. A día de hoy, con el material disponible de la archidiócesis de Toledo -lo editado, lo mal editado y lo inédito-, se puede valorar mejor su importancia trascendental en el siglo XII. Se han conservado numerosas litterae clausae (cartas cerradas o selladas) trasmitidas a Toledo, lo que mueve a concentrar en éste y otros puntos clave el examen de la evolución. Por cierto, los intercambios entre Roma y Toledo han sido el objeto de la tesis de un alumno mío, Andreas Holndonner; desde hace pocos años, vemos mucho más clara esta cuestión ${ }^{11}$.

P. Alguno de los asuntos tratados en esta reunión de Lisboa (en concreto la comunicación por escrito) remite directamente al proyecto diplomático que lleva desarrollando en el último decenio: una sección con entidad propia dentro de la Regesta Pontificum Romanorum: la Iberia Pontificia, que ya suma 5 volúmenes ${ }^{12}$. La colección Iberia

11 Andreas Holndonner, Kommunikation, Furisdiktion, Integration: das Papsttum und das Erzbistum Toledo im 12. Fabrbundert (ca. 1085-ca. 1185), De Gruyter, Berlín, 2014.

12 Regesta Pontificum Romanorum Iberia Pontificia. Ivbente Academia Gottingensi Congerenda cvravit Nicolavs Herbers. Iberia Pontificia sive Repertorivm privilegiorvm et litterarvm a romanis pontificibvs ante annvm MCLXXXXVIII Hispaniae et Portugalliae ecclesiis monasteriis civitatibvs singvlisque personis concessorom.

- vol. I: Dioeceses Exemptae Dioecesis Burgensis, congessit Daniel Berger, Vandenhoeck \& Ruprecht, Gottinga, 2013.

- vol. II: Dioeceses Exemptae Dioecesis Legionensis, congessit Iacobus Domínguez Sánchez, Vandenhoeck \& Ruprecht, Gottinga, 2013.

- vol. III: Provincia Toletana Dioecesis Palentina, congessit Daniel Berger, Vandenhoeck \& Ruprecht, Gottinga, 2015.

- vol. IV: Provincia Compostellana Dioeceses Abulensis, Salmanticensis, Cauriensis, Civitatensis, Placentina, congesserunt Frank Engel et José Luis Martin Martin, Vandenhoeck \& Ruprecht, Gottinga, 2016.

- vol. V: Dioeceses Exemptae Dioecesis Ovetensis. Provincia Bracarensis Dioecesis Astvricensis, congesserunt Iacobvs Domínguez Sánchez et Daniel Berger, Vandenhoeck \& Ruprecht, Gottinga, 2019 
Pontificia se presenta en tomos de tapas grises con letras doradas, como su matriz, la Regesta Pontificum Romanorum. Son libros sobrios y bellos. Según reza su portada, contiene el «Repertorio de los privilegios concedidos por los romanos pontífices antes del año 1198 a sedes e iglesias, monasterios, ciudades y personas singulares». Regestas y comentarios están escritos en latín, y sus portadas proclaman solemnemente que la Academia de Gottinga encargó a Nicolavs Herbers de su coordinación. El coordinador firma sus prólogos en alemán y castellano. En 2019, con ocasión de editarse el quinto volumen de los dedicados a las diócesis de León y Castilla, celebraba el resultado de la colaboración entre estudiosos de los dos países.

Casi un siglo después, $V d$. ha retomado a buen ritmo el proyecto «Göttinger Papsturkundenwerk» de Paul Fridolin Kehr (1860-1944), que en los años 20 del siglo pasado dirigió la publicación en dos tomos de las bulas pontificias relativas a Cataluña y a los reinos de Navarra y Aragón., ¿no es así? El pasado año 2020, Vd. y sus colaboradores editaron un volumen de «cartas papales en España», que parece el tercer volumen de la serie mencionada y publica las bulas de Castilla ${ }^{13}$. La segunda pregunta se refiere a cómo se articula esta labor con la Regesta Pontificum Romanorum, la otra iniciativa del aquel gran erudito.

R. Nuestro proyecto tiene tres pilares. El primero, «Archivos y Documentación», consiste en revisar todos los archivos y publicar la documentación pontificia, continuando la labor iniciada con los dos volúmenes Papsturkunden in Spanien referido a Cataluña y Aragón-Navarra de Kehr. Efectivamente, hemos editado un tercer dedicado a Castilla. Vamos a preparar otro Papsturkunden in Spanien del reino de León (incluyendo Galicia y Asturias, donde creo que será muy importante la documentación de Lugo). El quinto volumen de esta serie ya está publicado. Se trata del que Carl Erdmann († 1945) dedicó a Portugal, que además incluye datos de algunas comarcas gallegas.

$\mathrm{El}$ segundo pilar consiste en reconstruir los contactos pontificios de escala diocesana: es el mencionado programa Iberia Pontificia, que publica regestos de

En cada volumen se regestan los escritos papales a obispos y cabildos de las sedes, y a los monasterios enclavados en cada diócesis. Así mismo, se han elaborado introducciones históricas sobre los obispados, se valora la historiografía y la tradición textual, y se proporciona amplia información bibliográfica.

13 Daniel Berger, Klaus Herbers y Thorsten Schlauwitz (eds.), Papsturkunden in Spanien. Vorarbeiten zur Hispania (Iberia) Pontificia. III. Kastilien, De Gruyter, Berlín, 2020. Los 290 documentos publicados en este volumen fueron enviados por los papas a múltiples destinatarios del reino de Castilla en los siglos XI y XII; muchas de las bulas proceden del archivo de la catedral de Toledo, entre ellas varias desconocidas hasta ahora; el resto provienen de las diócesis castellanas de Palencia, Burgos, Osma, Segovia, Sigüenza y Cuenca. 
documentos, como se sabe. Kehr dirigió la primera fase de un proyecto de coleccionar las cartas papales por regiones y diócesis. Se inició con Italia y Germania Pontificia. Esos volúmenes están ahora casi acabados. La labor de la Gallia Pontificia solo cuenta con unos pocos volúmenes. Respecto a España, Kehr obtuvo la ayuda inestimable del Papa Pío XI, y de esta relación nace la Fundación Pius. También contó con el trabajo de varios investigadores independientes, como Carl Erdmann en Portugal, Peter Rassow en el Archivo Histórico Nacional de Madrid, Pascual Galindo Romeo, y José Rius Serra en Cataluña. Aunque solo llegó a publicar la documentación relativa a Cataluña y Navarra-Aragón, reunió materiales mucho más amplios.

La Guerra Civil y la II Guerra Mundial interrumpieron la tarea. Más tarde, otros investigadores han llevado a cabo trabajos parciales. Me refiero a Odilo Engels y Ludwig Vones.

Con la financiación de las Academias, reemprendimos un plan sistemático en 2006-2007. La situación es diferente y complicada. Teníamos que utilizar materiales de Paul Fridolin Kehr y sus colaboradores que ya tienen cien años. Las signaturas de archivo no son las mismas, ni el modelo de referencias, y no sabíamos lo que estaba hecho y lo que no. De forma que todo debe ser revisado e implementado. Pero hay una precisión importante, que da valor suplementario a la etapa de Kehr. Durante la guerra civil desaparecieron documentos y otros no se localizan hoy. En particular, es el caso de la sede de Sigüenza: su archivo fue destruido en la contienda, pero conservamos las trascripciones que se habían preparado, no sé si obra de Paul Fridolin Kehr, Peter Rassow o de Rius Serra.

En definitiva, éste es un nuevo proyecto. Daniel Berger y todo el equipo están trabajando intensamente, y hemos contado con mucha ayuda en España, en particular la de Santiago Domínguez Sánchez. Gracias al esfuerzo común también se ha publicado el volumen de las diócesis de Pamplona, Tarazona y Calahorra (a cargo de Frank Engel y Thomas Czerner) ${ }^{14}$, y está listo para su publicación el de Segovia y Sigüenza (con Daniel Berger). Estamos preparando Zamora (por cuenta de Santiago Domínguez y Frank Engel), y un volumen sobre la Iberia visigótica. Todos estos aparecerán en 2021.

En fin, el tercero de los pilares consiste en integrar las novedades que vamos hallando -en España y otros grandes espacios-, en la obra cronológica de Jaffé, antes evocada.

14 Regesta Pontificum Romanorum Iberia Pontificia... VI. Dioeceses Calagurritana, Tarazonensis et Pampilonensis. congesserunt Frank Engel et Thomas Czerner, Vandenhoeck \& Ruprecht, Gottinga, 2021. 


\section{CAMino DE SANTIAGO}

P. Estamos en el inicio de un nuevo año facobeo, los jubileos que se celebran en Compostela cada vez que la festividad de Santiago el Mayor cae en domingo. Esta ocasión está marcada por la tragedia de la covid. ¿ Cómo se desarrollará algo que tiene una naturaleza tan «presencial»? De momento, el carácter excepcional de la coyuntura queda en resalte: porque esta vez, el jubileo abarcará los años 2021 y 2022.

$V d$. forma parte del comité internacional de expertos del Camino de Santiago, y lleva mucho tiempo en este organismo, un observatorio privilegiado. ¿Cuál es su cometido? ¿Qué articulación mantienen con las instituciones - pienso en la Xunta de Galicia y el Arzobispado de Santiago de Compostela?

R. El comité de expertos inició sus tareas en los 90. A lo largo de este tiempo, ha conocido cambios de actividades, o de responsabilidades y de niveles de asesoramiento. Recuerdo especialmente la etapa de los gobiernos de Manuel Fraga al frente de la Xunta de Galicia. Considero que Serafín Moralejo y Fernando López Alsina, tuvieron un papel muy importante en los momentos iniciales, que estuvieron asociados a la inmensa movilización que precedió al Año Jacobeo de 1993 y, en concreto, a la gran exposición de Compostela ${ }^{15}$. El clima actual es de buenas relaciones con el gobierno Feijóo. En mi experiencia, no es lo mismo si el Camino de Santiago se considera fundamentalmente una cuestión de cultura o de turismo. Las valoraciones y las decisiones son distintas.

Nuestras obligaciones principales son dos. Somos un comité de carácter científico, cuyo cometido se centra en promover una aproximación al fenómeno jacobeo que se concreta en exposiciones, reuniones y congresos, velando por la publicación de todos sus resultados. En segundo lugar, sus miembros representan a los países donde la tradición jacobea tiene raíces profundas; esto incluye el interés por difundir su conocimiento y por establecer relaciones entre todos países.

Ahora bien, en estos momentos acude a la tumba del Apóstol muchísima gente de muchos más sitios, de diversas culturas, con intereses tan variados... ¿Hay un interés científico consistente entre ellos? ¿Cómo representarlos dentro

15 Serafín Moralejo y Fernando López Alsina (eds.) Santiago, Camino de Europa. Culto y cultura en la peregrinación a Compostela [catálogo de la exposición celebrada en el monasterio de San Martín Pinario de Santiago de Compostela, 1993], Madrid, Xunta de Galicia - Fundación Caja Madrid Arzobispado de Santiago de Compostela, 1993. El catálogo de las piezas viene precedido de una suma de estudios sobre las tradiciones jacobeas, las confraternidades, las rutas y el culto de Santiago a escala europea. El ambiente de este Año Santo estuvo alentado por el recuerdo de la visita del papa Juan Pablo II en agosto de 1989. 
del comité? ¿Hay personalidades aptas para asumir las obligaciones? Dentro del comité existen opiniones distintas.

Lo que estamos preparando es la celebración de un gran congreso en Compostela al comienzo de la primavera del año que viene (23-27 de marzo de 2022). Como formulaba el presidente del comité, el profesor Paolo Caucci von Saucken, se trata de hacer un balance de la investigación del culto jacobeo en los últimos decenios. Adelanto su título: «Santiago de Compostela. Caminos del saber, de andar y de creer». Naturalmente, todo esto queda pendiente de cómo evolucione la pandemia.

P. Nosotros los españoles -y pienso que los estudiosos en general-, damos un gran valor a la obra de Luis Vázquez de Parga, Fosé María Lacarra y Juan Uría sobre «Las Peregrinaciones a Santiago de Compostela» $(1948)^{16}$. Personalmente, la considero un ensayo de historia cultural singular, por su calidad, por su sentido experimental-pues se basa tanto en fuentes escritas como en trabajo de campo-, y por ser un estudio realmente aislado para su época ¿Qué significado tuvo y tiene para Vd.?

R. Toda la literatura jacobea posterior -la de quienes se han dedicado al estudio serio del Camino-, tiene como punto de partida esa obra. Todo, desde las rutas a la selección de documentos, está presente en ella.

P. A través de su memoria, a través de medio siglo de vivencias, estudios y responsabilidades, ¿qué rasgos le parecen más significativos del Camino como itinerario cultural europeo?

R. El Camino es «un camino a las reliquias», el caso más sobresaliente dentro de las rutas que pueden tener este significado. Es la tumba de un apóstol situada en el extremo del Occidente. Coincide en parte con una vieja ruta o calzada romana. Había un gran interés en señalar el interés de la ruta. El Liber Sancti facobi cumple la tarea de subrayar la entidad de toda esta ruta. Esto se hace patente en los milagros del Apóstol que benefician a los que van por el Camino, o en el libro V, la guía de la ruta. En él se pone de relieve la «subordinación» de los centros de devoción del Camino (pienso en Saint Sernin de Toulouse, Sainte Foy de Conques...) a su destino final, lo que enfatiza su carácter de via sacra, como observó Manuel Cecilio Díaz y Díaz. De modo que los hitos sagrados del Camino contienen elementos imprescindibles para hacer una verdadera peregrinación.

16 Luis VÁzQueZ de PARGa, José María LaCARRa y Juan URÍA RiU, Las peregrinaciones a Santiago de Compostela, CSIC, Madrid, 1948, 3 tomos (Edición facsímil por Iberdrola - Gobierno de Navarra, Pamplona, 1992, con nota previa de Ángel J. Martín Duque y Apéndice. Bibliografía 1948-1992, por Fermín Miranda García). 
Desde el otro extremo del arco cronológico, me parece que en 1986, los políticos del momento idearon el Camino como aportación española a una Europa de las naciones diversas.

P. Su tarea en el seno de este comité forma parte de un «activismo jacobeo» en Alemania que le ha llevado a presidir la principal asociación jacobea del país. Supongo que se siente cómodo con tanta actividad, en un país de dilatada tradición compostelana, peregrina, andariega en general... Hace treinta años, $V d$. mostró que la fama de la peregrinación a Compostela llegaba hasta Alemania ya en los años $930 . .$.

R. Sí, analicé una noticia que proviene de la famosa abadía de Reichenau, situada en una isla del lago de Constanza. El dato se halla en un texto hagiográfico de esa fecha; curiosamente, cuenta la historia de un ciego que fue a Santiago para curarse, pero no obtuvo allí remedio; en cambio, el prodigio tuvo lugar en Reichenau. Más allá de ser una forma estilística de la hagiografía, el relato señala que Compostela era un destino acreditado en pos del milagro, aunque este caso dé una imagen negativa ${ }^{17}$.

P. Y abora, ¿cómo percibe la sensibilidad hacia el fenómeno jacobeo en su país?

R. Tengo el honor de presidir la principal asociación alemana, Deutsche Sankt Jakobus Gesellschaft. Lo jacobeo está muy activo en Alemania. Tanto, que una de nuestras labores es controlar la proliferación de rutas que a veces solamente se pretenden «camino de Santiago». Se trata de canalizar iniciativas y seleccionarlas. Nuestra asociación ha publicado además una veintena de estudios científicos (serie Jacobus-Studien; cfr. https://deutsche-jakobus-gesellschaft.de/ ueber-uns/veroeffentlichungen/), para fundamentar y clarificar los caminos y las huellas del culto. En gran medida, estos estudios son fruto de las reuniones anuales de nuestra Sociedad.

Desde luego, muchos alemanes aman caminar, y en concreto frecuentar las rutas jacobeas: pero en este momento la pandemia ha restringido tanto los movimientos... Hay mucha gente que desea salir y espera poder hacerlo pronto.

Entre nuestros intereses recientes se halla el estudio de las insignias de peregrinación, un testimonio de la amplitud del culto jacobeo (y por extensión, del gran número de sitios de peregrinación que existieron en una época antigua). Hasta hace poco, nos habíamos dedicado a las regiones católicas. Pero estamos descubriendo cada vez más riqueza en los países bajo influencia protestante, desde las regiones del norte de Alemania a Escandinavia y los países bálticos. Este

17 Klaus HeRBERS, El primer peregrino ultrapirenaico a Compostela a comienzos del siglo X y las relaciones de la monarquía asturiana con la Alemania del Sur, en Compostellanum, 36 (1991), pp. 255-264; ahora en ID., Papado, peregrinos y culto jacobeo [ver n. 2], pp. 71-82. 
tipo de señales nos permite valorar los vestigios de la tradición peregrina que hubo hasta la Reforma del siglo XVI.

P. No puedo olvidarme de cierta crisis: el robo del Códice Calixtino del archivo de la sede compostelana en el verano de 2011, que Vd. había trabajado tanto... ¿Qué recuerda de este acontecimiento? ¿Podemos esperar serenamente que esto no vuelva a suceder?

R. Fue un momento decisivo. Fue un acontecimiento horrible para el mundo científico. Había desaparecido el monumento principal del culto jacobeo. Desde luego, el robo da cuenta muy bien de la importancia de este documento clave, al mismo tiempo que subraya que quien lo hizo, sabía lo que estaba haciendo $^{18}$. Persiste el problema general de si los archivos eclesiásticos son seguros en España: ésta era una pregunta frecuente de la prensa local. En mi opinión, el de Compostela es más seguro ahora. Incluso considero otro hecho como un elemento disuasorio: que existe una edición facsímil del Liber Sancti Iacobi.

P. La literatura jacobea ha experimentado un enorme crecimiento en los últimos decenios y, dentro de ella, la contribución de Klaus Herbers es muy destacada. Hemos tenido ocasión de comentar algunos de sus trabajos. Como su tesis sobre el culto a Santiago en el siglo XII y el Liber Sancti Iacobi, centrada en las relaciones entre la religión y la sociedad medieval ${ }^{19}$. En 1979, mientras la estaba elaborando, tuvo ocasión de conocer en Compostela a Fernando López Alsina, que también preparaba la suya sobre la ciudad del Apóstol en la Alta Edad Media. De allí surgió la amistad y una colaboración fluida que se mantiene al cabo de cuatro décadas entre el profesor de Santiago y el de Erlangen.

Elogiando su publicación, Pierre-André Sigal, uno de los grandes especialistas en los milagros medievales, escribió en la revista Francia (1985, $\left.n^{\circ} 13\right)$, que «gracias a Klaus Herbers, el Liber Sancti Jacobi se nos muestra renovado. La originalidad de este bistoriador es atenerse, más que sus predecesores, al papel del compilador de la obra, y de situarlo en su contexto religioso, social y económico. De este modo, aparecen destacadas convergencias con el movimiento de reforma eclesiástica y la ética caballeresca». A lo que añadía la confianza en que pronto se dispusiera de una edición integral del famoso códice.

18 Las hemerotecas guardan memoria del episodio. Ver, por ejemplo, en El País (17/07/2011), el reportaje principal de la sección Revista de Verano, formado por estos artículos: José Luis CoRRAL, Así robaron el Códice (ficción), pp. 45-46; Jesús DUVA, La policía rastrea a usuarios y trabajadores del archivo, pp. 4-47. José Luis MARTÍN MARTíN, Los «hermanos» del «Codice Calixtino», p. 47. Son tres trabajos muy diferentes: el relato de un colega caracterizado por sus novelas históricas; la hipótesis policial, que se demostró muy bien orientada; y el contexto cultural trazado por otro medievalista, gran conocedor de archivos catedralicios (y colaborador de Iberia Pontificia).

19 Klaus Herbers, Der Fakobuskult des 12. Fabrbunderts und der «Liber Sancti Iacobi». Studien über das Verbältnis zwischen Religion und Gesellschaft in hoben Mittelalter, Franz Steiner, Wiesbaden, 1984. 
Nuestro propio autor se encargó de llevarla a cabo junto con Manuel Santos Noya. La transcripción anotada del Liber se presentó como anticipo del Año Santo 1999, en un sólido volumen de buen papel, fácil lectura y gran formato ${ }^{20}$.

R. En los años que siguieron a mi tesis -precisa Klaus Herbers-, mi proyecto de edición del Liber Sancti facobi coincidió con los de otros estudiosos. Don Manuel Cecilio Díaz y Díaz, catedrático de Santiago y maestro de maestros, tenía interés en llevarlo a cabo. También el latinista Millán Bravo, catedrático de Valladolid, que se proyectaba hacia Alemania especialmente y deseaba articular a su alrededor un grupo de trabajo. Al final, lo que se hizo en España y en otros países, fueron traducciones a distintas lenguas del famoso Libro V, la «Guía del Peregrino» ${ }^{21}$. Por cierto, merece reseñarse la calidad de la traducción francesa de Jeanne Vieillard, que era muy anterior, pues data de 1938. Fue la obra pionera ${ }^{22}$.

P. Esta fase tuvo un relieve particular para el autor. En 1999 publicó junto a Robert Plötz su estudio sobre los relatos de peregrinos jacobeos, y también su libro sobre la versión política del culto medieval al Apóstol. La primera parte del libro de relatos sirve de contexto; trata en general del culto de las reliquias y del culto jacobeo, de sus orígenes y su difusión. La segunda parte resulta singular porque analiza las memorias de una veintena de viajeros-caminantes-peregrinos a Santiago entre los siglos XV y XVIII (aparte de la mencionada «Guía del Peregrino» del siglo XII ${ }^{23}$. Y Herbers subraya:

R. Mantuve con Robert Plötz una intensa relación, de la que da prueba esta obra. Esa relación también data de los tiempos de nuestras tesis, en cierta forma paralelas. Se concreta en nuestros trabajos conjuntos sobre el Camino de Santiago en Alemania y en alemán, y tiene aspectos muy personales: hicimos la peregrinación juntos dos veces. Él fue el primer presidente de la Deutsche St. Fakobus

20 Liber Sancti Iacobi. Codex Calixtinus, Klaus Herbers y Manuel Santos Noia (eds.), Santiago de Compostela, Xunta de Galicia, 1998. Conviene precisar que el denominado «libro de Santiago» es un «códice» formado por cinco partes, también llamadas «libros»: (I) Conjunto de textos para la liturgia de Santiago; (II) Colección de 22 milagros merced a la intercesión del Apóstol; (III) Relato de la traslación del cuerpo de Santiago a Compostela; (IV) Pseudo-Turpín, crónica de las supuestas campañas de Carlomagno en España; (V) Libro de la peregrinación, atribuido a Aymeri Picaud, clérigo de Parthenay-le-Vieux, en Poitou (oeste de Francia). El códice se compuso en la primera mitad del siglo XII.

21 Millán Bravo LozANo (trad. y notas), Guía del peregrino medieval («Codex Calixtinus»), Centro de Estudios del Camino de Santiago, Sahagún, 1989.

22 Jeanne VIEILlaRD, Le guide du pèlerin de Saint-facques de Compostelle: texte latin du XIIe siècle, Librairie Philosophique J. Vrin, Paris, 1984 (1ª ed. 1938).

23 Klaus Herbers y Robert PlÖTZ, Caminaron a Santiago. Relatos de peregrinaciones al «fin del mundo», Xunta de Galicia, 1999 (versión alemana 1996). 
Gesellschaft. Y perteneció al comité de expertos del Camino de Santiago hasta su fallecimiento en 2017.

P. Respecto a otro libro, su «Santiago político», aprecio cómo su trabajo da una enorme importancia al vínculo del apóstol con la monarquía: los reyes asturianos y luego Fernando I, ilustran una idea: que «Santiago estuvo estrechamente unido a los intereses dinásticos de Asturias y León en la primera época», y así continuó estándolo después, con la contribución señera de Fernando II y Alfonso IX de León ${ }^{24}$. Las fuentes literarias y los diplomas, espúreos o no, sustentan este argumento. Se puede decir que, si al comienzo de nuestras conversaciones subrayaba el profesor Herbers el estrecho vínculo entre Roma y Santiago, esta perspectiva revela otro factor imprescindible para entender el apogeo del «Hijo del Trueno».

En España, Alemania y otros países, él ha seguido publicando estudios sobre el culto de Santiago y sus cultivadores ${ }^{25}$. Por un momento, la conversación se orienta hacia las obras en torno al tema jacobeo que le han llamado la atención en los últimos tiempos. Y se detiene en un par de obras singulares.

Aunque el cine mezcle con frecuencia lo real y lo esotérico, estima que bay otros testimonios relevantes: así, la película Nur die Füße tun mir leid. 900 Kilometer Jakobsweg, de Gabi Röbrl, una cineasta autodidacta. Se trata de un trabajo documental al bilo de las vivencias de los peregrinos y de la propia autora, que filmó el material mientras hacía la peregrinación ${ }^{26}$.

La otra obra que escoge es la reciente novela de Luis García Jambrina El manuscrito de barro. La describe rápidamente como una trama de aire picaresco, situada en el Camino de Santiago a la altura de 1525, un momento clave de la bistoria europea -con la reforma protestante en auge, la rebelión de los campesinos alemanes y los frescos ecos de la victoria de Pavía. Valora en ella cómo el autor juega a combinar elementos reales y ficticios, cuyos guiños deleitan al especialista. No es una obra para neófitos, añade, pero

24 Klaus Herbers, Política y veneración de santos en la Península Ibérica. Desarrollo del «Santiago político», Fundación Cultural Rutas del Románico,, Poio 1999. Una versión resumida en La monarquía, el papado y Santiago de Compostela en el Medioevo [actas del V congreso de Estudios Jacobeos de 1999, ed. 2001], pp. 101-119, ahora en ID., Papado, peregrinos y culto jacobeo... [ver n. 2], pp. 1-31.

25 Además de remitir a su repetidamente citada selección de artículos (véase la nota anterior), retengo a modo de ejemplo: Klaus Herbers, Facobus - der Heilige Europas. Geschichte und Kultur der Pilgerfahrten nach Santiago de Compostela, Patmos, Düsseldorf, 2007, donde Santiago es presentado como «el santo de Europa» al tratar de la historia y la cultura de las peregrinaciones a Compostela.

26 Reflexionar durante el trayecto sobre lo poco que se necesita para ser feliz, parece haberle inspirado un título que significa «solo siento pena por mis pies»; también hay una versión inglesa del film, fust Sorry for my Feets. 
se puede disfrutar enormemente ${ }^{27}$. Y en efecto. Ya lo revela en las primeras páginas la caracterización del protagonista Fernando de Rojas, del cardenal Tavera (en cuya máscara mortuoria se ha inspirado el novelista), o del archivero Elías do Cebreiro (que de inmediato recordará a los jacobípetas la entrañable figura de don Elias Valiña Sampedro, «el cura de O Cebreiro».

Don Elías Valiña (1929-1989), llevó a cabo una tarea titánica en favor de la peregrinación desde su parroquia, en el puerto que da entrada de Galicia desde El Bierzo. Estaba basada en documentar, cartografíar y escribir sobre el corredor jacobeo, y en acoger a los peregrinos. Hoy, el aspecto más visible de su labor son las conchas y flechas amarillas sobre fondo azul que festonean el Camino: es la señal más popular para que el peregrino sepa que transita por la ruta adecuada, la que ba conseguido desvanecer la sensación de inseguridad que, como a tantos otros, acompañó al joven Klaus Herbers en su primera caminata.

Este recuerdo se asocia a una última cuestión. Como queda indicado, $V d$. se ha interesado profundamente por los peregrinos-viajeros que han legado memorias de sus andanzas. Entre ellos, dos alemanes de fines del siglo XV: Felix Fabri y Hieronymus Münzer.

Sobre Felix Fabri, tengo como referencia un articulo que analiza el relato «Peregrinos a Sión», escrito por el fraile dominico Félix Schmid, más conocido por Fabri, su apellido latinizado ${ }^{28}$. Fue un famoso predicador que vivió en el convento de Ulm, al sur de Alemania, de 1468 a su muerte en 1502. A diferencia de Münzer, como después veremos, los peregrinos a Sión «viajan en el espíritu». Es decir, ¿esto significa que no es propiamente el relato de un viaje real, sino una relación de sitios de peregrinación que se visitan simbólicamente?

R. Sí, es muy importante el concepto de «peregrinación espiritual». Hay que tener en cuenta que éste era un trabajo destinado al convento de sus hermanas de religión, las dominicas de Ulm. Ellas no iban a viajar físicamente. El padre Fabri, que desde luego fue un gran viajero y especialmente visitó Roma y Tierra Santa, les preparó una colección de dietas que cubren casi todos los días del año, aproximadamente unas 360. Sus destinos son Jerusalén, Roma y Santiago de Compostela. Yo estimo que con ello dio forma a un sistema hagio-crono-

27 Luis García JAmbrina, El manuscrito de barro, Planeta, Barcelona, 2021. De momento, es la última de una serie de cinco novelas de su autor, cuyo protagonista es Fernando de Rojas, el conocido autor de La Celestina.

28 Klaus Herbers, Sacralizar el tiempo y el espacio. Visitar lugares sagrados en los siglos XII y XV, en María Isabel DEL VAL VALDIVIESo, Pascual MARTínEZ SOPENA (dirs.), Castilla y el mundo feudal, Homenaje al profesor fulio Valdeón, III, Junta de Castilla y León - Universidad de Valladolid, Valladolid, 2009, pp. 567-581. 
geográfico, pues conjugaba desde una perspectiva sacra la veneración religiosa, el ritmo cotidiano y los escenarios vividos.

P. Hieronymus Münzer da nombre a cierto proyecto al que Klaus Herbers ha dedicado una parte de actividad por largo tiempo. Recordemos que Münzer, médico en Nuremberg, hizo un extraordinario viaje por Europa Occidental en los años 1494-95, deteniéndose particularmente en España. Lo relevante es que escribió una amplia memoria en latín de su experiencia, asi como la aguda mirada que refleja este libro de viajes. Un comunicado de prensa de la universidad de Erlangen daba cuenta del inicio del proyecto en mayo de $2003^{29}$. ¿Ha cumplido los amplios objetivos previstos?

R. La iniciativa me ha ocupado durante 17 años. En este otoño, hace unos pocos meses, se han publicado por fin sus resultados, que componen un libro de más de 800 páginas. Una introducción de 300 páginas precede a la edición del texto en latín, más sus notas e índices ${ }^{30}$.

Es muy importante tener en cuenta que Jerónimo Münzer no solo peregrinó a Santiago, sino que viajó por toda la península y otros sitios. Cuando llegó a la tumba del apóstol, se atuvo al principio de fe, con alguna ambigüedad: «no vimos, pero tenemos que creer...», vino a decir ${ }^{31}$. Era un humanista viajero, vinculado estrechamente a un amplio grupo de humanistas de la ciudad donde vivía, Nuremberg, y esta ciudad tuvo, sin duda alguna, un papel capital en la cultura alemana de su tiempo. El extenso relato de Münzer es resultado de toda esta serie de elementos y los enriquece con su propia experiencia. En Münzer late la idea de interculturalidad.

29 Las siguientes líneas extractan la descripción del proyecto en dicho comunicado de prensa, obra de Klaus Herbers. Hieronymus Münzer, rico ciudadano de Nuremberg, se pudo permitir un viaje deslumbrante que lo llevó desde su ciudad a Francia, España, Portugal y los Países Bajos. En su cuaderno de viaje (Itinerarium), relata lo que vio y experimentó. La variedad de sus intereses, que se aplican a los más diversos aspectos de la vida política, económica y social, es asombrosa. Aunque nunca pierde de vista a su ciudad natal, cuyos vecinos fueron los primeros lectores de su diario. Quizá por eso, la comparación es tan importante para Münzer. Tales observaciones son una excelente fuente sobre los viajes de fines del XV, de la historia de los países visitados por Münzer, y como testimonio de las percepciones de los denominada «expansión europea» hacia 1500. El autor concluía que «es sorprendente que el viaje de Münzer apenas haya sido objeto de estudios extensos hasta ahora».

30 Hieronymus MÜNZER, Itinerarium. Klaus Herbers (ed.), Wiebke Deimann, René Hurtienne, Sofia Meyer, Miriam Montag, Lisa Walleit (cols.), Tina B. Orth-Müller (n.), Harrassowitz Verlag, Wiesbaden, 2020. Esta obra inicia una nueva subserie de diarios de viajes medievales en los Monumenta Germaniae Historica.

31 Sepultus autem creditur sub altari magno cum duobus suis discipulis, quorum unus a dextris et alius a sinistris. Corpus autem a nullo visum est. Etiam anno Domini 1487, dum rex Castelle ibi esset, non vidit. Sola fide credimus, que salvat nos homines (Münzer, Itinerarium, pp. 214-215). 
P. Por cierto, $V d$. ha percibido una sutil línea que distingue entre «viajar a pie»y «peregrinar ${ }^{32} \ldots$

R. Haciendo un juego de palabras, en Alemania decimos entre nosotros y a los peregrinos noveles: «¿Todavía caminas o ya estás peregrinando?». Porque entiendo que la diferencia entre viajar a pie y peregrinar forma parte de un proceso de desarrollo personal. Recuerdo a Edmond-René Labande cuando, haciendo otro juego de palabras en francés, reflexionaba: «Peregrinar, es rezar con los pies».

\section{INTERCULTURALIDAD}

P. Desde el año 2010, Vd. es editor de la revista Archiv für Kulturgeschichte, lo que viene a reconocer su contribución y su impulso en el campo de la bistoria cultural. Es oportuno recordar algunas de las empresas que ha venido desarrollando y conozco más de cerca. Fueron proyectos que ponían de relieve las relaciones entre el Sacro Imperio y España en la Edad Media, que comparaban ambos espacios políticos a escala de grandes problemas, o que ampliaban la discusión sobre la noción de frontera al conjunto europeo $0^{33}$. Estos libros están presididos por su mirada a la bistoria de la cultura, una bistoria dinámica donde las trasferencias y las reinterpretaciones juegan un papel fundamental. En realidad, todo esto se conjuga con su tarea de impulsor de proyectos de investigación intercultural, que Vd. ha centrado en el espacio bispánico.

R. Esta revista se fundó hace más de un siglo. Nuestra percepción de la historia cultural no es la misma que en otros países. Prefiero una idea muy amplia de «historia cultural», ajena a las precisiones. Toca a muchos aspectos, incluida la cultura material. Toda la historia puede ser objeto de una mirada cultural, y este es un dato clave para favorecer la interrelación.

P. Lo cierto es que la interculturalidad y una mirada antropológica son elementos que recorren su obra: desde sus estudios generales sobre la historia de España y Portugal

32 Klaus Herbers, ferónimo Münzer en Santiago. La importancia de la tradición jacobea en la narración de su viaje por Europa Occidental (1494-1495), en Javier GÓMEZ-MONTERO (ed.), Topografías culturales del Camino de Santiago. Kulturelle Topographien des Jakobsweges. Actas del Simposio Internacional A rosa dos aires da xeografia xacobea en Europa (peregrinos, literatura e iconografía) celebrado en Hamburgo (6.-8.10.2014), Peter Lang, Frankfurt am Main, 2016, pp. 205-217.

33 Julio Valdeón, Klaus Herbers, Karl Rudolf (eds.), España y el «Sacro Imperio». Procesos de cambios, influencias y acciones recíprocas en la época de la «europeización» (siglos XI-XIII), Universidad de Valladolid, Valladolid, 2002. Klaus HERBERS, Nikolas JASPERT (eds.), «Das kommt mir spanisch vor». Eigenes und Fremdes in den deutsch-spanischen Beziehungen des späten Mittelalters, Lit Verlag, Münster, 2004. Klaus HERBERS, Nikolas JASPERT (eds.), Grenzräume und Grenzüberschreitungen im Vergleich. Der Osten und der Westen des mittelalterlichen Lateineuropa, Akademie Verlag, Berlin, 2007. 
con la importancia que asigna a la Iglesia en la evolución de las sociedades, al mundo de la peregrinación que se acaba de evocar en el epígrafe anterior. Mi impresión es que Herbers sale al paso de quienes perciben la Iglesia como un avatar relevante dentro los «poderes feudales». Coincidimos en que la reivindicación del significado primordial de la Iglesia en la sociedad de una «larga Edad Media» que se prolonga mucho más allá del 1500, debe mucho a grandes figuras del medievalismo como Facques Le Goff, Alain Guerreau o Fosé Angel García de Cortázar. Lo que, por otra parte, nos sirve para indicar que no se trata tanto de un problema entre estudiosos «cristianos» $y$ «laicos» (... «idealistas» $y$ «materialistas», u otras dicotomías al uso), como de análisis matizados y capaces de integrar la complejidad histórica.

Desde ese punto de vista, ¿Qué tendencias le parecen más relevantes en el milenio medieval hispánico?

R. Una de las grandes cuestiones de la historia hispánica son los orígenes de la Edad Media. Considero que España se cristianiza desde el norte de África, lo que es casi singular a escala continental. También considero que España forma parte de Europa ya desde sus inicios: que es europea en la medida que evoluciona en los siglos de la temprana Edad Media como evoluciona Europa.

La diversidad cultural hispánica es difícil de definir. Es importante destacar que la Reconquista creó culturas políticas diferentes. En todas ellas, el factor religioso fue muy importante. Cabe matizar que este factor se intensificó tras el cambio de milenio, y llegó a ser decisivo en los siglos XI y XII.

En los siglos posteriores, con la reconquista casi acabada, cristalizaron elementos muy diferentes, a modo de mosaico. La noción de cultura tiene avatares varios. Hay una cultura del norte cristiana y eclesiástica, presidida por Santiago de Compostela, Montserrat o Guadalupe, y hay otra orientada al Mediterráneo (a Italia, Sicilia, Grecia, así como a Granada). Pero destacaré la variedad percibida por el viajero Münzer, a quien vuelvo otra vez: él prima la economía en el área mediterránea, la religión en Granada, la política en la corte de los Reyes Católicos -a quienes visitó en Madrid, mostrando su anhelo porque Fernando conquistara Jerusalén y su acuerdo con la política antijudía. Respecto a Portugal, resalta las expediciones en África y el Atlántico, mientras en Salamanca la cultura es, ante todo, universitaria...

P. En nuestras conversaciones se ban planteado cuestiones que afectan a muchas facetas de la investigación de Klaus Herbers, aunque no a todas. Por recordar una, aludiré a su interés por la escritura y el género epistolar, objeto de una publicación reciente y con 
voluntad de continuidad ${ }^{34}$. $Y$ en este sentido, es como deseo hacerle una pregunta final: ¿qué proyectos ha previsto para el futuro?

R. Lo primero, tengo por delante concluir lo que ya he indicado al tratar de las fuentes de la historia papal en Roma y en España.

Además, ahora estoy preparando un gran proyecto sobre el canonista Burkhardo de Worms (†1025). Su colección canónica representa más de 100 manuscritos para colacionar. Una colega, Cornelia Scherer, se va a encargar paralelamente de la Colección canónica hispana.

Y junto con otra colega de Berlín, Birgit Aschmann, proyecto una historia de la península ibérica medieval a partir de personajes-clave: San Isidoro, Eulogio de Córdoba, Almanzor, El Cid, la reina Urraca, Alfonso X, Raimundo Lulio. Esta se prolongará con otros modernos (de Juana la Loca a Franco, pasando por Goya...)

P. Estas páginas han procurado recoger la sustancia de prolongadas sesiones con el profesor de Erlangen. Desde hace más de veinte años nos unía una cálida relación, que han fortalecido estas muchas horas de trabajo ante la pantalla, impuestas por las circunstancias. Pero no ha babido asomo de melancolía. He tenido ocasión de felicitarle por el nacimiento de su undécimo nieto y hemos celebrado entre sonrisas otros lances. Como cuando, madrugador y deportista, nos sorprendía en las Semanas de Estudios Medievales de Estella a la hora de desayunar. Él llegaba de nadar temprano en las aguas del Ega.

34 Thomas Deswarte, Klaus Herbers, Hélène SiRAntoine (eds.), Epistola 1. Écriture et genre épistolaires, $I V^{e}-X I^{e}$ siècle, Casa de Velázquez, Madrid, 2018. 
